\title{
IMPACT OF WORKING SPEED ON SOIL PARTICLES TRANSFER DURING SECONDARY SOIL TILLAGE
}

\begin{abstract}
Josef HŮLA, Czech University of Life Sciences Prague, Faculty of Engineering, Kamycka 129, 16521 Prague 6 - Suchdol, Czech Republic, hula@tf.czu.cz

Petr NOVÁK, Czech University of Life Sciences Prague, Faculty of Engineering, Kamycka 129, 16521 Prague 6 - Suchdol, Czech Republic, novakpetr@tf.czu.cz (corresponding author)

Displacement of soil particles by erosion can be seen as a major threat to the quality of agricultural land in the conditions of Czech Republic. While the effects of water and wind erosion have long been investigated and reported, the effect of soil tillage technology on soil particles translocation are relatively new area of agriculture research. Soil tillage may contribute to the undesirable translocation of soil particles towards lower-lying parts of fields especially on slopes. The effect of soil tillage implements on soil particle translocation has not been sufficiently explained yet. The object of this research was to assess the influence of different operating speed of power harrow on soil particle translocation during secondary tillage (soil preparation). Measurements to determine the displacement of soil particles were performed in location Nesperská Lhota in the Central Bohemia Region. Measurements were performed on a sandy loam cambisol after harvest spring cereals (oat for sillage production). To indicate displacement of soil particles was used grit of white limestone (size 10-16 mm). Limestone was put down into the trench with known position orthogonal to the direction of working operations. Subsequently were performed working operations in the specified sequence. Limestone particles were counted and weighed in each section. It was detected by measuring the different nature of displacement. Statistical significance of differences in the weight of translocated particles was evaluated for different operating speeds of power harrow from 4.5 to $12 \mathrm{~km}^{\mathrm{h}} \mathrm{h}^{-1}$.
\end{abstract}

Keywords: power harrows, tillage erosion, seedbed preparation.

\section{INTRODUCTION}

Erosion is the most serious threat to soil in the Czech Republic. Together with technogenic compaction and decarburizing, erosion reduces soil quality for long time. While wind and water erosion is a long-standing issue, tillage erosion is among the new research directions. Its influence is not insignificant, all the context and mechanisms of effect on the soil are not known yet.

Soil tillage can contribute to the undesirable soil particles translocation towards to lower lying parts of fields especially on slopes. The effect of soil tillage implements on translocation of soil particle has not been sufficiently explained yet. A large impulse to study of tillage erosion was given by Govers' investigations (Govers et al. 1999). Van Muysen et al. (2002) emphasizes that tillage erosion is a crucial problem. In the last years interest in the study of tillage erosion has gradually been increasing. Yet there is a lack of data and evaluated results documenting the effect of the working tools on soil particle translocation during soil tillage. Van Oost et al. (2006) also states that soil losses due to erosion caused by its tillage every year could be higher than soil losses as a result of erosion caused by surface water runoff.

Li et al. (2007) summarized that there is more information about the effects of primary soil tillage on soil particle translocation than in secondary tillage. In general, there is a lack of data about the translocation of soil particles through a soil cultivation by machines with powered working tools.

Van Muysen et al. (2002) and da Silva et al. (2004) considered operating speed and working depth during soil tillage as the main factors participating on translocation of soil particles. The lack of experimental data is also related to the influence of the machines operating speed on the displacement of soil particles.

Lobb et al. (1995) stated that tillage erosion accounts for at least $70 \%$ of the total loss of soil on hilltops. There is not a sufficient description of the influence of particular groups of machines and their implements on soil with regard to the translocation of soil particles - it is mainly applicable to secondary soil tillage and sowing (Lobb et al. 1999).

\section{MATERIALS AND METHODS}

Measurements of the effect of different operating speed on translocation of soil particles during secondary tillage were carried out at September 2017. Measurement took place at locality Nesperská Lhota at Central Bohemia Region 60

Copyright (C) 2017 The Authors. Published by Aleksandras Stulginskis University. This is an open-access article distributed under the terms of the Creative Commons Attribution License (CC-BY 4.0), which permits unrestricted use, distribution, and reproduction in any medium, provided the original author and source are credited. 
$\mathrm{km}$ near the Prague (GPS 49.690435, 14.815578). Measurements took place on a gently sloping $\left(0.8^{\circ}\right.$ downslope orientation of machine movement) field with sandy loam Cambisol after harvest of common oat for green forage. Before measurements soil was ploughed to the depth $0.2 \mathrm{~m}$. Next step was secondary tillage of soil by the Ostroj seedbed combinator. Undisturbed samples (Kopecky cylinders with volume $100 \mathrm{~cm}^{3}$ ) were taken for determination of the basic physical properties of soil at a tillage depth that were subsequently analysed in the laboratories of the CULS Prague. Soil moisture was determined with the Theta Probe sensor (Delta devices). To measure the translocation of soil particles by secondary tillage was used power harrows Rabe Werk with working width $2.5 \mathrm{~m}$.

Zetor-12045 (90 kW) tractor was used as a pulling machine. Operating speeds of $4.5 \mathrm{~km} \cdot \mathrm{h}^{-1}, 7 \mathrm{~km} \mathrm{~h}^{-1}$ and $11 \mathrm{~km} \mathrm{~h}^{-1}$ were chosen. Soil moisture at a depth of its tillage was $12.2 \%$ by volume (before loosening), bulk density was $1.43 \mathrm{~g} \mathrm{~cm}^{-3}$, total porosity $43.7 \%$ by volume.

White limestone grit with particle size 12-16 mm was used like a marker to evaluate the transfert of soil particles. Before soil tillage limestone particles were incorporated into grooves of $0.20 \mathrm{~m}$ in width and $0.33 \mathrm{~m}$ in length. Depth of grooves was $0.1 \mathrm{~m}$. Three grooves were used for each variant. The longer side was oriented perpendicularly to the direction of subsequent passes of power harrows. The groove depth was chosen to match the working depth of tiller tools (Fig. 1).

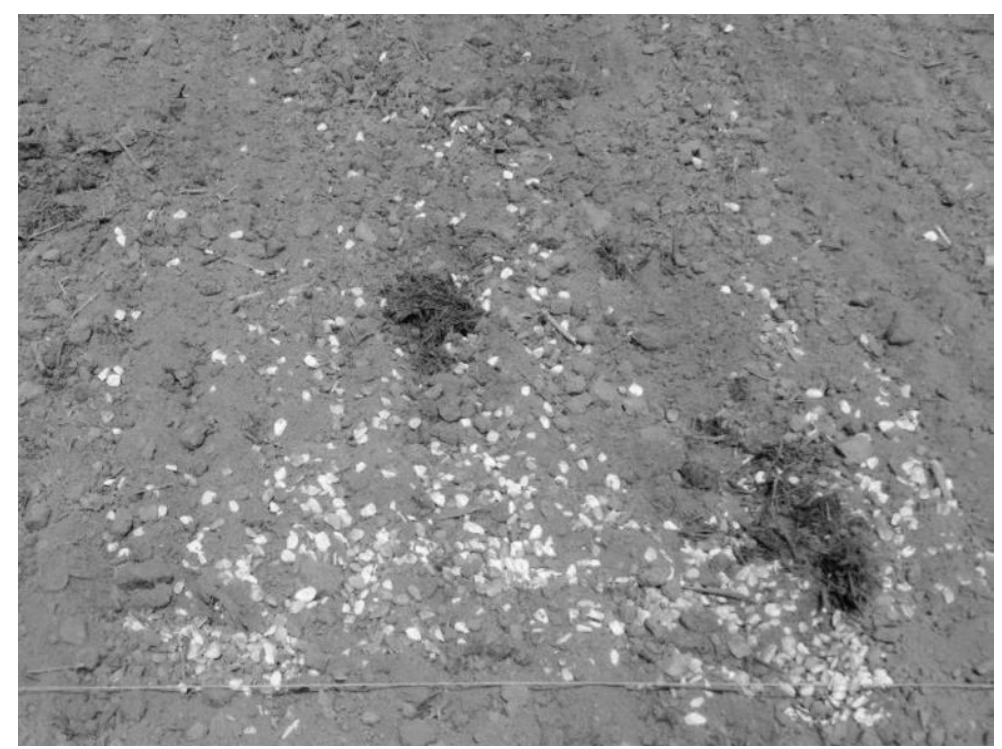

Figure 1. Limestone tracers after secondary tillage

After the set of a tractor with the respective implement (3 operating speeds) passed across the field, the tracers were picked by hand from the soil in lengthwise segments of $0.30 \mathrm{~m}$ in the direction of the machine movement- segments were marked by metal plates pressed into the topsoil. After the tracers were picked from the soil, their weight was detected in each segment as an indicator of the soil particle translocation by secondary tillage. For data processing MS Excel (Microsoft, USA) and Statistica 12 (Statsoft, USA) were used with the analytical tool ANOVA for statistical evaluation of results, specifically by Tukey’s HSD test.

\section{RESULTS AND DISCUSSION}

Fig. 2 shows the translocation of soil particles during tillage with a power harrows. The graph illustrates decreasing weight of translocated particles with increasing lengthwise distance at all measured operating speeds (4.5, 7 and $11 \mathrm{~km} \mathrm{~h}^{-1}$ ). The selected work speeds are within the possible operating range of this machine type. This graph also indicates the effect of operating speed on particle translocation. The translocation pattern can be described by the power regression method when a very strong relationship is reached in all studied cases in the given range of measurements (see Fig. 2).

At a higher operating speed $\left(11 \mathrm{~km} \mathrm{~h}^{-1}\right)$ power harrows translocated a larger amount of particles, to a longer distance. At low lengthwise distances $(0-0.6 \mathrm{~m})$, there are no big differences in the amount of moving particles. Surprisingly, the smallest number of transferred particles is at a distance of 0.6-0.9 $\mathrm{m}$ for the middle work speed. This trend is not confirmed in other segments. In all other segments there is a clear trend, when the smallest number of particles is transported during the lowest working speed. The results clearly show the effect of the work speed on the particle transfer. This is probably due to the shifting of the entire surface layer of the soil during its processing by the power harrows. This phenomenon is undoubtedly influenced by the amount of organic matter on the surface and in the subsurface layer of soil. Organic matter causes larger quantities of particles to move away from the original location. This transfer will be adversely affected by sloping of land.

Quite surprising is the comparison of results at medium and highest work speeds. There is not much difference in most segments evaluated (see Figure 2 and Table 1). This may be due to the lower effect of the harrows on the size of the soil aggregates in the processing layer. Power harrows are sensitive to the change in the working speed and with its growth there is a decrease in the quality of work. The larger soil particles can then create a layer that is pushed in front of the 
work tools of power harrows. This phenomenon can affect much more work tools. This phenomenon will be more noticeable on heavier soils.

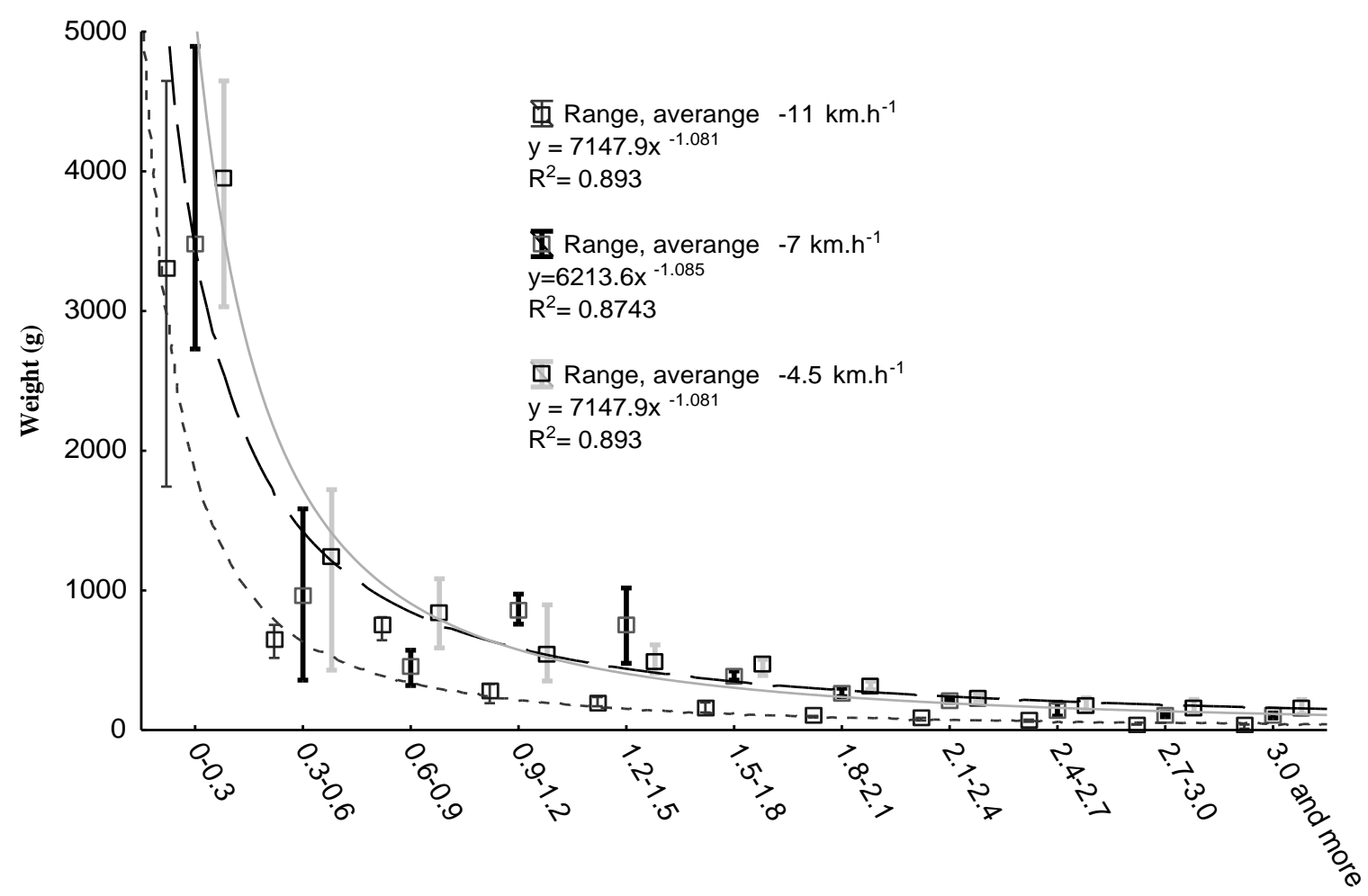

Lenghtwise distance (m)

Figure 2. Translocation of soil particles during tillage with a power harrows

Table 1 shows average values of the weight of translocated particles and statistically significant differences are shown by means of letters indices. The rest of the grid remained in its original place. There was no way to move all tracers. The translocation pattern and the effect of speed are clearly visible. At a shorter distance from the original location fewer particles were translocated at the lowest operating speed. However, these differences were below the statistical significance level without exception. In the other segments, the values during lowest speed is most different. The values at the middle and highest speeds are relatively similar. This is quite surprising. In the intervals from 0.9 to $3 \mathrm{~m}$ statistically significant differences were found out between the particular speeds (see Table 1). At a speed of $11 \mathrm{~km} \cdot \mathrm{h}^{-1}$ the most distant particle was $8.1 \mathrm{~m}$ from the original location. At a speed of $9 \mathrm{~km} \cdot \mathrm{h}^{-1}$ the most distant particle was at $5.9 \mathrm{~m}$ and at a speed of $4.5 \mathrm{~km} . \mathrm{h}^{-1}$ it was $5.1 \mathrm{~m}$. The majority of the particles are translocated to a short distance, then the translocation intensity decreases very rapidly. It is caused mainly by the effect of harrows when the soil is carried away with tools along the whole tilled depth of the soil profile. The transport effect will surely be influenced by an organic matter amount on the soil surface and in the subsurface layer of soil (it was only minimum of organic matter on surface).

Table 1. Average translocation of particles (g) with a power harrows in a lengthwise direction and marked out homogeneous groups (Tukey's HSD test)

\begin{tabular}{|c|c|c|c|}
\hline Distance (m) & 11 km.ha $^{-1}$ & 7 km.ha- $^{-1}$ & 4.5 km.ha $^{-1}$ \\
\hline $0-0.3$ & $3955^{\mathrm{a}}$ & $3487^{\mathrm{a}}$ & $3300^{\mathrm{a}}$ \\
\hline $0.3-0.6$ & $1245^{a}$ & $955^{\mathrm{a}}$ & $656^{\mathrm{a}}$ \\
\hline $0.6-0.9$ & $849^{a}$ & $453^{\mathrm{b}}$ & $746^{a}$ \\
\hline $0.9-12$ & $550^{\mathrm{a}}$ & $853^{\mathrm{a}}$ & $281^{\mathrm{b}}$ \\
\hline $1.2-1.5$ & $493^{a}$ & $750^{a}$ & $198^{\mathrm{b}}$ \\
\hline $1.5-1.8$ & $466^{\mathrm{a}}$ & $383^{\mathrm{a}}$ & $152^{\mathrm{b}}$ \\
\hline 1.8-2.1 & $313^{\mathrm{a}}$ & $265^{\mathrm{a}}$ & $97^{b}$ \\
\hline 2.1-2.4 & $231^{\mathrm{a}}$ & $211^{a}$ & $81^{\mathrm{b}}$ \\
\hline 2.4-2.7 & $179^{\mathrm{a}}$ & $145^{\mathrm{a}}$ & $66^{\mathrm{b}}$ \\
\hline $2.7-3.0$ & $167^{\mathrm{a}}$ & $109^{\mathrm{a}}$ & $41^{\mathrm{b}}$ \\
\hline 3.0 and more & $164^{\mathrm{a}}$ & $103^{\mathrm{b}}$ & $35^{c}$ \\
\hline
\end{tabular}


Most similar studies have focused on primary soil tillage. Van Muysen et al. (2006) uncovered that at typical soil tillage including use of primary tools (mouldboard plough, chisel tiller and disc tiller) the average translocation rates is in the range between 0 and $0.9 \mathrm{~m}$. This was confirmed by our previous measurements. But at soil tillage technology using soil preparation by power harrows, we found displacement of soil particles into greater distances (up to $3 \mathrm{~m}$ ). This was caused by displacement of soil particles in the soil surface layer during secondary tillage. The presented results are consistent with the conclusions of Tiessen et al. (2007) about the crucial influence of the type of working tools acting on the soil, their geometry and adjustment of machines.

The influence of topography and trajectory of machine movement in sloping conditions cannot be ruled out. Dercon et al. (2006) stressed the risk of soil translocation in the direction of downslope before tillage. In their study they demonstrated the negative effect of tillage erosion on soil qualitative parameters in conditions of light Cambisols. The results reveal the need of changing the movement direction during secondary soil tillage. Such a measure will increase the costs of soil tillage on sloping lands. A potential decrease in labor productivity and an increase in soil tillage costs were reported by Schumacher et al. (1999). Higher costs would be compensated by reduction in soil degradation and piecemeal increase in yields and quality of crop production. Soil quality is essential for sustainable land management.

\section{CONCLUSIONS}

Power harrows are machine that are used on a large scale for soil tillage (especially together with drill machines). The operating speed is an important factor influencing the quality of their work and area performance. For disc and tine cultivators is a typical working speed between $5-10 \mathrm{~km} \cdot \mathrm{h}^{-1}$. Therefore it is important to straighten the influence of the different working speeds on soil particles transfer. This was confirmed in the performed measurements. The results of evaluation of soil particle transfer at different operating speed of power harrows can contribute to better knowledge of the share of tillage treatments in soil erosion process. The results clearly show the effect of the work speed on the particle transfer. It was confirmed that the choice of machines for soil tillage can substantially influence the intensity of undesirable soil translocation. Research on tillage erosion is not completed. It is necessary to further development this themes with other working tools and soil conditions. This paper represents only measurements of one type of soil cultivation machine at different working speeds.

\section{ACKNOWLEDGEMENTS}

Supported by the Ministry of Agriculture of the Czech Republic - Project no. QJ1520028.

\section{REFERENCES}

1. Da Silva, J.R.M., Soares, J.M.C.N., Karlen, D.L. 2004. Implement and soil condition effect on tillage-induced erosion. Soil \& Tillage Research, Vol. 78, pp. 207-216. https://doi.org/10.1016/j.still.2004.02.009

2. Dercon, G., Deckers, J., Poesen, J., Govers, G., Sanchez, H., Ramirez, M., Vanegas, R., Tacuri, E. \& Loaiza, G. 2006. Spatial variability in crop response under contour hedgerow systems in the Andes region of Ecuador. Soil \& Tillage Research, Vol. 86, pp. 15-26. https://doi.org/10.1016/j.still.2005.01.017

3. Govers, G., Lobb, D.A., Quine, T.A. 1999. Tillage erosion and translocation: emergence of new paradigm in soil erosion research. Soil and Tillage Research, Vol. 51, pp. 167-174.

4. Li, S., Lobb, D.A., Lindstrom, M.J. 2007. Tillage translocation and tillage erosion in cereal-based production in Manitoba, Canada. Soil and Tillage Research, Vol. 94, pp. 164-182. https://doi.org/10.1016/j.still.2006.07.019

5. Lobb, D.A., Kachanoski, R.G., Miller, M.H. 1995. Tillage translocation and tillage erosion on shoulder slope landscape positions measured using ${ }^{137} \mathrm{Cs}$ as a tracer. Canadian Journal of Soil Science, Vol. 75, pp. 211-218. https://doi.org/10.4141/cjss95-029

6. Lobb, D.A. \& Kachanoski, R.G. 1999. Modelling tillage erosion in topographically complex landscapes of southwestern Ontario, Canada. Soil \& Tillage Research, Vol. 51, pp. 261-278. https://doi.org/10.1016/S0167-1987(99)00042-2

7. Schumacher, T.E. Lindstrom, M.J., Schumacher, J.A., Lemme, G.D. 1999. Modeling spatial variation in productivity due to tillage and water erosion. Soil \& Tillage Research, Vol. 51, pp. 331-339. https://doi.org/10.1016/S0167-1987(99)00046-X

8. Tiessen, K.H.D., Lobb, D.A., Mehuys, G.R., Rees, H.W. 2007. Tillage erosion within potato production in Atlantic Canada: II. Erosivity of primary and secondary tillage operations. Soil \& Tillage Research, Vol. 95, pp. 320-331. https://doi.org/10.1016/j.still.2007.02.009

9. Van Muysen, W., Govers, G., Van Oost, K. 2002. Identification of important factors in the proces of tillage erosion: the case of mouldboard tillage. Soil and Tillage Research, Vol. 65, pp. 77-93. https://doi.org/10.1016/S0167-1987(01)00282-3

10. Van Oost, K., Govers, G., de Alba, S., Quine, T.A. 2006. Tillage erosion: a review of controlling factors and implications for soil quality. Progress in Physical Geography, Vol. 30, Iss. 4, pp. 443-466. https://doi.org/10.1191/0309133306pp487ra

11. Van Muysen, W.V., Oost, K.V., Govers, G. 2006, Soil translocation resulting from multiple passes of tillage under normal field operating conditions. Soil \& Tillage Research, Vol. 87, pp. 218-230. https://doi.org/10.1016/j.still.2005.04.011 